\title{
A window into the Anthropocene through lake-sediment records in central Chile
}

\author{
Magdalena Fuentealba ${ }^{1,2}$, C. Latorre ${ }^{1,2}$, M. Frugone-Álvarez ${ }^{1,2}$, P. Sarricolea ${ }^{3}$ and B. Valero-Garcés ${ }^{4}$
}

\begin{abstract}
Stable nitrogen isotopes on organic matter from lake sediments in central Chile combined with reconstructions of land-use and cover change show the magnitude of human influence and the onset of the Great Acceleration.
\end{abstract}

\section{The Anthropocene in central Chile}

The Anthropocene has been proposed as a new geological epoch where humankind has become a major driver of the Earth's biosphere and surface processes to an extent that can be readily observed in the sedimentary record (Crutzen and Stoermer 2000). The Anthropocene Working Group of the International Commission on Stratigraphy (https://stratigraphy.org) has recently defined the starting point of the Anthropocene at around $1950 \mathrm{CE}$, which marks a period of dramatic change in magnitude and rate of the global human activity (the Great Acceleration; Zalasiewicz et al. 2019). However, this date remains a point of contention as agricultural impacts (and associated impacts) have been increasing throughout the Holocene (Ellis et al. 2016; Ruddiman 2019; Zalasiewicz et al. 2019).

Nitrogen, carbon, and phosphorus biogeochemical cycles can all affect primary productivity, and their alteration can cause serious environmental problems such as cultural eutrophication and contamination of terrestrial and aquatic ecosystems. Records of past variations in biogeochemical cycles can help unravel the timing and intensity of the Anthropocene (Wolfe et al. 2013; Zalasiewicz et al. 2019). Humans have had important impacts on the landscape of the Pacific coast of central Chile at least since the Spanish colonial period (16th to 18th centuries). These have been associated with agriculture development, increased fire regimes, and deforestation of native species (Armesto et al. 2010; Gayo et al. 2019). Nowadays, most human impact is related to increasing demands for tree plantations of exotic species (especially Pinus radiata and Eucalyptus globulus).

We studied two coastal lakes from central Chile to examine the structure and timing of the Anthropocene and the onset of the Great Acceleration. For this, we compared landuse and cover change (LUCC) with stable nitrogen isotopes on lake organic matter $\left(\delta^{15} \mathrm{~N}\right)$ and multiproxy analyses from lake sediments. The Laguna Matanzas watershed $\left(30 \mathrm{~km}^{2}\right.$ surface area; Fig. $\left.1 \mathrm{~b}\right)$ was mainly occupied by native forest and grassland areas in 1975 CE, but by 2016 CE, tree plantations covered a third of the total area. At Lago Vichuquén, only $1 \%$ of the watershed (535.3 km² surface area; Fig. 1c) was covered by exotic tree plantations in $1975 \mathrm{CE}$; however, these increased up to $66 \%$ by 2016 CE.

\section{Watershed-lake dynamics inferred from the sediment record}

The $\mathrm{Br} / \mathrm{Ti}$ ratios in lake sediment from coastal lakes of central Chile are commonly elevated with high organic carbon content, indicating higher lake productivity (Frugone-Álvarez et al. 2017; Fuentealba et al. 2020). Similarly, fluctuations in $\delta^{15} \mathrm{~N}$ in lake records have been used as an indicator of changes in paleoproductivity and/or watershed disturbances (Das et al. 2009; Torres et al. 2012)

Historic LUCC in the Laguna Matanzas watershed began during the Spanish colonial period with a Jesuit settlement in $1627 \mathrm{CE}$ and the development of a livestock ranch. After the Jesuits were expelled from South America in $1778 \mathrm{CE}$, the ranch reached more than 40,000 head of cattle around 1800 CE. During this first period, the watershedlake dynamics displayed moderate-to-low productivity (Br/Ti; Fig. 2) with elevated sediment input as indicated by our geochemical proxies (Ti; Fig. 2; Fuentealba et al. 2020). Sediment $\delta^{15} \mathrm{~N}$ values from the 14th to 19th centuries were relatively high, probably reflecting $N$ inputs from cow manure and soil particles that typically generate higher sediment $\delta^{15} \mathrm{~N}_{\mathrm{om}}$ values (Fig. 2). From the 19th to mid-20th centuries, these overall patterns did not change. The $\delta^{15} \mathrm{~N}$ and total nitrogen (TN) values were slightly lower than during the Colonial Period and changes in both were in phase and relatively synchronous.

The implementation of the Chilean Forestry Law Decree of 1931 (DFL n²65) contributed to a strong development of forestry that was coeval with decreased sediment input (low Ti) from the watershed and slightly increased lake productivity (higher $\mathrm{Br} / \mathrm{Ti}$ ). Until the 1970s, the Laguna Matanzas watershed was mostly covered by native forest, and grassland areas were intended for livestock grazing (Fig. 1; Fuentealba et al. 2020). From the 1980s onwards, sediment $\delta^{15} \mathrm{~N}_{\text {om }}$ values decreased, reaching their lowest values in the entire sequence at ca. 2000 CE. During the 21st century, the sediment $\delta^{15} \mathrm{~N}$ values increased in tandem with the highest TN values seen in the record (Fig. 2). The increased lake productivity, the sharp change in $\delta^{15} \mathrm{~N}_{\mathrm{om}}$ trend, and the decreased sediment input during the last few decades has been synchronous with the replacement of intensive livestock grazing by intensive ag riculture and forestry practices (Fuentealba et al. 2020).
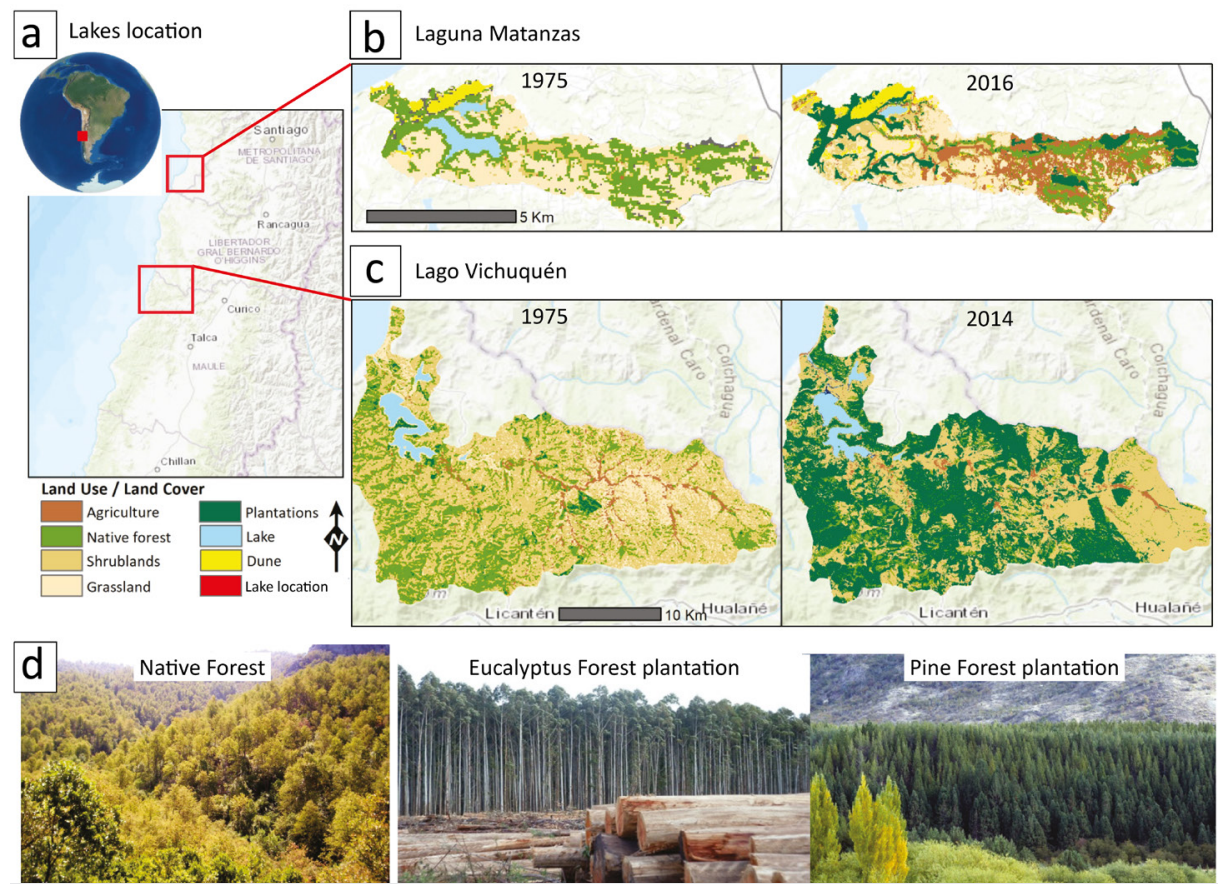

Figure 1: (A) Location of Laguna Matanzas and Lago Vichuquén in South America. (B) and (C) Land-use and cover changes in both watersheds from 1975 CE and 2014 (Lake Vichuquén) and 2016 (Lake Matanzas) CE (map sources: Esri, HERE, Garmin, World Topographic Map). (D) Examples of native forests compared with tree plantations in central Chile. 


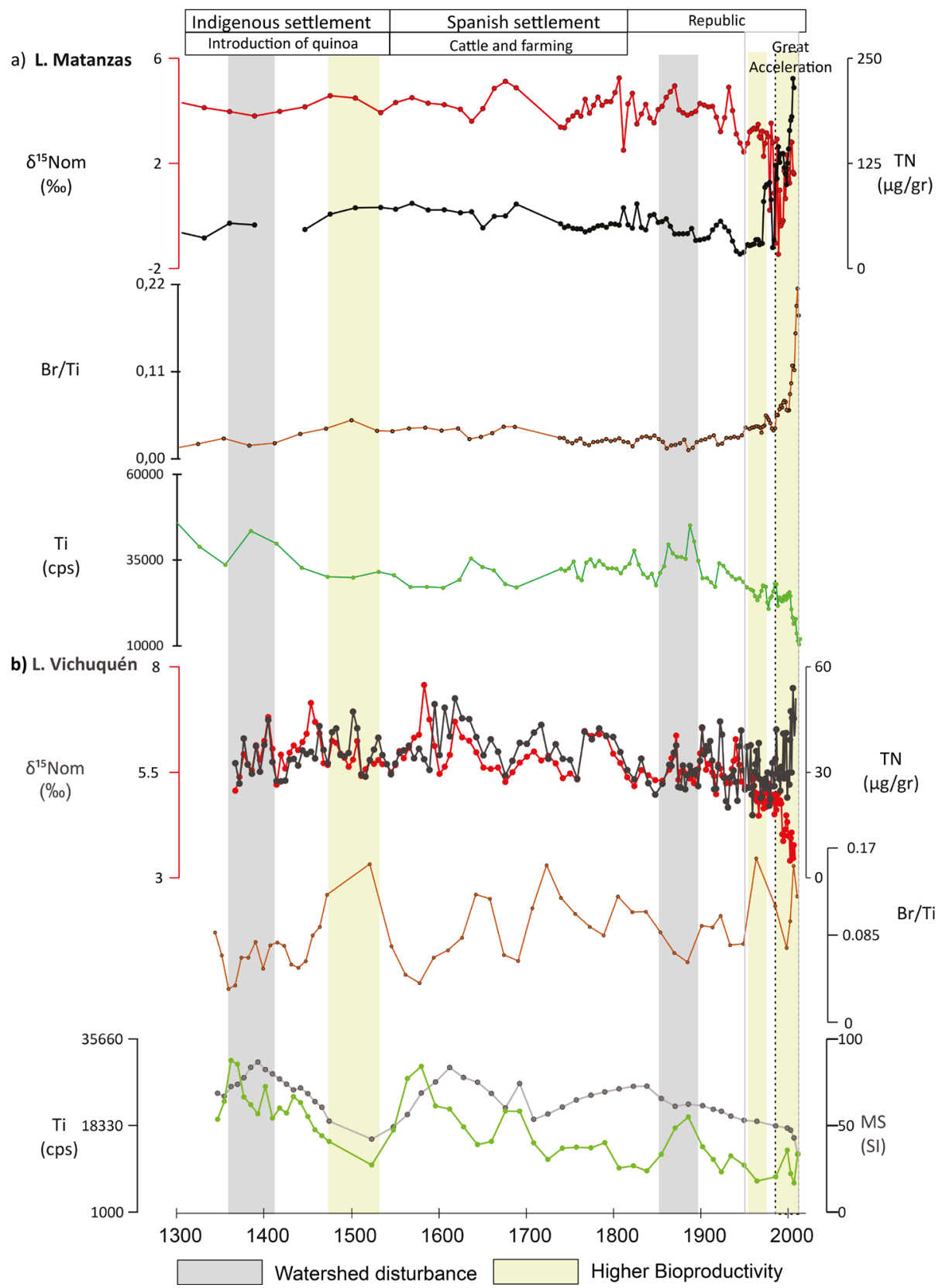

Figure 2: Anthropogenic influences on changes in the $N$ availability and lake productivity during the last six centuries in central Chile (Laguna Matanzas and Lago Vichuquén). Higher sediment $\delta^{15} \mathrm{~N}_{\mathrm{om}}$ values (red line) covaried with the TN (black line), indicating higher lake productivity ( $\mathrm{Br} / \mathrm{Ti}$ ) after periods of watershed disturbance (magnetic susceptibility, Ti).

Land use during the colonial period in Lago Vichuquén was characterized by agriculture, cattle ranching, and mining under the Encomienda (feudal) system (Vidal and Ramírez 1985). Historical documents show that before $1580 \mathrm{CE}$, the Vichuquén watershed was occupied by Indigenous communities dedicated to small-scale farming, extracting wood, and mining activities. The sediment $\delta^{15} \mathrm{~N}_{\text {om }}$ values from this period covary with $\mathrm{TN}$, indicating pulses of enhanced $\mathrm{N}$ input from the watershed were likely linked to an increase in land use and sediment input (indicated by changes in magnetic susceptibility and Ti content in Fig. 2).

From the onset of the 19th to the mid-20th centuries, $\delta^{15} \mathrm{~N}_{\mathrm{om}}$ and TN values decreased slightly, most likely related to lowered sediment input from the watershed until the second half of the 19th century. In contrast, the last part of the 20th century witnessed accelerated changes in the watershed as native forests, meadows, and shrublands were quickly replaced by exotic tree plantations (Fig. 1). These changes were synchronous with a major regime shift in the nitrogen cycle as observed by an increase in TN along with lowest $\delta^{15} \mathrm{~N}_{\text {om }}$ values seen in the record.

\section{The $\delta^{15} \mathbf{N}_{\text {om }}$ lake-sediment record} as a tracer of the Anthropocene

Numerous records indicate that the onset of the Great Acceleration in the Northern Hemisphere was around 1950 CE (e.g. Holtgrieve et al. 2011; Rose 2015; Zalasiewicz et al. 2019). However, the timing and magnitude of human activities were likely different between and within the hemispheres. Our results from Laguna Matanzas and Lago Vichuquén show elevated TN concentrations in tandem with the lowest sediment $\delta^{15} \mathrm{~N}$ values in the entire record during the $1980 \mathrm{~s}$ (Fig. 2). Thus, human activities associated with exotic tree plantations clearly had major impacts on the watershed-lake dynamics and nitrogen cycling in central Chile, several decades after the onset of the Great Acceleration. Although nitrogen dynamics respond to limnological processes as well, both lakes crossed a critical threshold, not seen in more than three centuries, during the 1980s due to regional processes associated with national policy changes and government subsidies.

Our study shows that during the historical period in Chile it is not necessarily the presence of human activities per se that alters watershed-lake dynamics, but rather the magnitude and intensity of such activities associated with major land-use and cover changes. The increase in tree plantations and intensive agriculture over the last 40 years (since the late 70 s and early 80 s) has contributed to a shift in sediment input and nutrient transfer to Laguna Matanzas and Lago Vichuquén, affecting productivity in a way that is unprecedented during the last 500 years. Though the Anthropocene and the Great Acceleration have been formally defined globally, we note that local and regional impacts often produce major changes in sedimentary records that are often at odds with these definitions. In the case of heavily populated central Chile, these impacts began with intense activity associated with extensive exotic tree plantations that started in the 1980s, three decades after the beginning of the Great Acceleration.

\section{AFFILIATIONS}

'Pontificia Universidad Católica de Chile, Santiago, Chile

${ }^{2}$ Institute of Ecology and Biodiversity (IEB), Santiago, Chile

${ }^{3}$ Universidad de Chile, Santiago, Chile

${ }^{4}$ Instituto Pirenaico de Ecología (IPE-CSIC), Zaragoza, Spain

\section{CONTACT}

Magdalena Fuentealba:

magdalena.fuentealba@gmail.com

\section{REFERENCES}

Armesto J et al. (2010) Land Use Policy 27: 148-160

Crutzen P, Stoermer EF (2000) Glob Change Newsl 41: $17-18$

Das B et al. (2009) J Paleolimnol 42: 167-181

Ellis E et al. (2016) Nature 540: 192-193

Frugone-Álvarez M et al. (2017) J Quat Sci 32: 830-844 Fuentealba M et al. (2020) Sci Rep 10: 5864

Gayo E et al. (2019) Elementa 7: 15

Holtgrieve G et al. (2011) Science 334: 1545-1548

Rose N (2015) Env Sci Technol 49: 4155-4162

Ruddiman W (2019) Prog Phys Geogr 43: 345-351

Torres IC et al. (2012) J Paleolimnol 47: 693-706

Vidal S, Ramírez O (1985) Vichuquén: 400 años. La Prensa press, $255 \mathrm{pp}$

Wolfe A et al. (2013) Earth Sci Rev 116: 17-34

Zalasiewicz J et al. (Eds) (2019) The Anthropocene as a Geological Time Unit: A Guide to the Scientific Evidence and Current Debate. Cambridge University Press, 331 pp 